\title{
THE GENUS SCAPHIELLA (ARANEAE, OONOPIDAE) IN CENTRAL AMERICA AND THE WEST INDIES*
}

\author{
By Arthur M. Chickering \\ Museum of Comparative Zoology
}

This is the third paper in the series planned for publication on the various genera in the family Oonopidae from Central America and the West Indies.

As I have frequently stated in my published papers, I am deeply indebted to members of the staff of the Museum of Comparative Zoology, Harvard University, for aid and encouragement for many years in the pursuit of my studies. Grants GB-1801 and GB-5013 from the National Science Foundation have made it possible for me to carry on extensive collecting activities in Panama, Costa Rica and the West Indies during the past four years, and to continue my work in the Museum of Comparative Zoology. My thanks are extended to the following for the loan of types and other specimens to aid me in more completely understanding the genus under consideration: Dr. J. G. Sheals and Mr. D. J. Clark of the Department of Zoology, British Museum (Natural History); Dr. Willis J. Gerstsch, American Museum of Natural History, New York City; Dr. E. Kritscher, Naturhistorisches Museum, Wien.

The types of all new species described in this paper together with my entire collection of this genus will be deposited in the Museum of Comparative Zoology.

\section{Genus Scaphiella Simon, I891}

The type species is Scaphiella cymbalaria Simon, based upon a male and a female from St. Vincent, B. W. I. Since the recognition of the genus in I891 a number of species have been described from South America, Central America, Mexico and the southwestern part of the United States. Scaphiella ula Suman has recently been described from Oahu, Hawaii but I think this species belongs in a different genus. More than thirty years ago I first became interested in this genus and since that time I have accumulated a rther large number of specimens from Central America and the West Indies now apparently separable into twelve distinct species. I failed to collect $S$. cymbalaria Simon during my brief visit to St. Vincent, B. W. I. in October, I966 but I have had this species for study from the British Museum (Natural History). Males of the genus

*Manuscript received by the editor January 15, 1968 

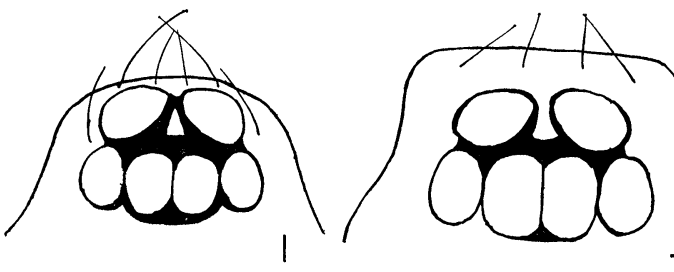

3

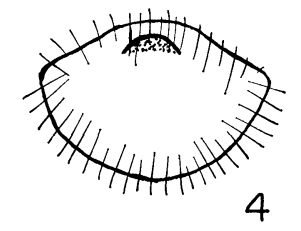

4
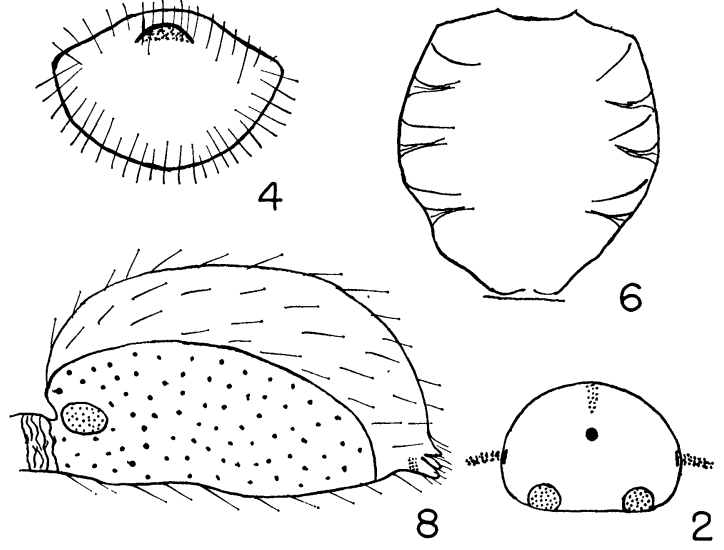

2

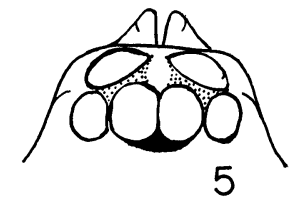

Figures 1-2. Scaphiella agocena sp. nov. Fig. 1. Eyes from above. Fig. 2. Epigynal area from below. Figures 3-4. Scaphiella curlena sp. nov. Fig. 3. Eyes from above. Fig. 4. Epigynal area from below. Figs. 5-9. Scaphiella cymbalaria Simon. Fig. 5. Eyes and bases of chelicerae from above. Fig. 6 . Sternum of male from below. Fig. 7. Left male palpal tarsus; prolateral view. Fig. 8. Female abdomen; left side. Fig. 9. Epigynal area from below.

are difficult to separate into species with certainty; they seem to be very consistent in following the generic palpal tarsal pattern but specific differences within this pattern are frustratingly difficult to recognize. Females, on the other hand, appear to be much more easily separable into species, especially, if we emphasize the features of the epigynal area which has usually received little attention in the past. It should also be noted that the matching of males and females is also somewhat problematical and errors are to be expected. I feel, however, fairly safe in the way this has been done in the present paper. The most important features of the genus observed during my study of the group may be stated as follows: The whole body is strongly chitinized, especially in males. The carapace is of 
moderate height, about half as tall as wide; the median thoracic groove or pit is lacking or very obscure. There are six eyes in two rows and in a compact group. ALE are close together; the posterior row is nearly straight but usually slightly procurved or, occasionally, slightly recurved. Chelicerae of moderate size and without special features except the curious black spines first seen in $S$. barroana Gertsch and $S$. williamsi Gertsch; the type species male also has a curious cone-shaped projection in front near the base of each chelicera (Fig. 5) but this has not been seen in any other species; there may also be an occasional minute tooth along the fang groove. Maxillae usually somewhat modified, especially in males. Lip without special features as far as observed. The sternum is somewhat scutiform; convex; commonly with a series of marginal lobes separated by shallow grooves but these may be greatly reduced or absent; usually extended only to bases of fourth coxae which are usually well separated; coxae tend toward being globose or subglobose. Legs: usually 4123 in order of length; strongly chitinized; probably with two tarsal claws throughout; true spines appear to be lacking but stiff hairs or bristles sometimes regarded as spiniform occur on certain segments; trichobothria have been observed on certain segments of legs and palps but they are easily overlooked. Male palp: in $S$. gertschi Chickering and $S$. scutata sp. nov. only the left palpal tarsus is fully developed but in all other males studied both palps are fully developed; the tarsal structural pattern is consistently followed and with great similarity among all species studied; all segments except the tarsus little if at all modified. When the unitarsal condition was first noted it was regarded as an anomaly but now it is clearly shown to be the normal condition in the two species just named. In females the palpal tarsus appears to lack a terminal claw but is somewhat enlarged (Fig. 46). Abdomen: considerably compressed laterally but the degree of compression is variable; in males there is an extensive dorsal acutum (Fig. 19) covering nearly the whole dorsum and extending laterally to approach the dorsolateral extension of the conspicuous ventral scutum; the group of closely associated spinnerets are usually surrounded ventrally and laterally by a narrow sclerite in both sexes. In females the dorsal scutum is lacking and, hence, there is always a middorsal unchitinized, whitish stripe of varying width; the epigynal area is usually quite distinctive but obscurely so and is of considerable help in determining species; considerable variation has been noted in the appearance of this region in certain species. 
Although some uncertainties still plague the author of this paper it seems at this time that a total of twelve species of the genus Scaphiella Simon must be recognized from the region under consideration. This list may be given as follows: Scaphiella agocena sp. nov.; Scaphiella barroana Gertsch; Scaphiella curlena sp. nov.; Scaphiella cymbalaria Simon; Scaphiella gertschi Chickering; Scaphiella kalunda sp. nov.; Scaphiella schmidti Reimoser; Scaphiella scutata sp. nov.; Scaphiella septella sp. nov.; Scaphiella simla sp. nov.; Scaphiella weberi sp. nov.; Scaphiella williamsi Gertsch.

Key to male Scaphiellae from Central America and the West Indies

Ia. Species with only the left palpal tarsus fully developed (gertschi, scutata)

Ib. Species with both palpal tarsi fully developed (barroana, cymbalaria, kalunda, schmidti, septella, simla, weberi, williamsi) .... 3

2a. Embolus arising from a relatively broad and angular base as in Figure 29; palpal femur somewhat inflated .... S. scutata, p.

2b. Embolus arising from a narrower and more rounded base as in Figure Io; palpal femur not inflated ................... S. gertschi, p.

3a. Embolus arising distal to the middle of the palpal tarsus (cymbalaria, kalunda, schmidti, septella) ....................................... 4

3b. Embolus arising at about the middle or proximal to the middle of the palpal tarsus (barroana, simla, weberi, williamsi) ........ 7

4a. Sternum with conspicuous grooves and marginal lobes

S. cymbalaria, p.

4b. Sternum without conspicuous grooves or lobes (kalunda, schmidti, septella)

5a. ALE separated from one another by about two fifths of their diameter S. kalunda, p.

5b. ALE nearly or quite contiguous to one another (schmidti, septella)

6a. Embolus arising from the side of a rounded tubercular base (Fig. 23)

S. schmidti, p.

6b. Embolus arising directly from the surface of the palpal tarsus without a tubercular base

S. septella, p.

7a. Embolus arising directly from a broad, bulbous base (Fig. 2I, Gertsch, I94I) …...................................... S. barroana, p.

7b. Embolus not arising as given above (simla, weberi, williamsi) .. 8

8a. Embolus arising directly from the surface of the tarsus but with a minute tubercle contiguous to its base (Fig. 19, Gertsch, 194I) S. williamsi, p. 
8b. Embolus not arising as given above (simla, weberi)

9a. ALE fairly well separated from one another (Fig. 42); palpal femur only moderately inflated

S. simla, p.

9b. ALE slightly separated from one another (Fig. 48); palpal femur considerably inflated

S. weberi, p.

No satisfactory key for the separation of the females in this genus has been devised.

Scaphiella agocena sp. nov.

Figures I-2

Holotype. The female holotype is from Curaçao, Nederlands Antilles, $3 \mathrm{~km}$ north of Savonet, December 28, 1962. Collected by Dr. H. W. Levi. The male is unknown and there are no paratypes. The name of the species is an arbitrary combination of letters.

Description. Total length $1.58 \mathrm{~mm}$, exclusive of the somewhat porrect chelicerae; including the bases of the chelicerae total length is $\mathrm{I} .66 \mathrm{~mm}$. Carapace $.57 \mathrm{~mm}$ long; $.4 \mathrm{I} \mathrm{mm}$ wide opposite second coxae where it is widest; .I $4 \mathrm{~mm}$ tall; nearly level along median region to beginning of posterior declivity the first half of which is very steep and with lower half only moderately so; with several stiff bristles along median region the most prominent of which are at top of declivity; with a fine granulation on the surface of the lower part of the declivity; remainder of surface generally smooth and shining. Eyes: six in a compact group; posterior row gently procurved and occupying about two thirds of width of carapace at that level; ratio of eyes $\mathrm{ALE}: \mathrm{PME}: \mathrm{PLE}=5: 4.5: 4$; $\mathrm{ALE}$ separated by slightly less than I/5 of their long axis; separated from PME by nearly half their long axis; narrowly separated from PLE; PME contiguous to one another by fully one fourth of their circumference and contiguous to PLE at one point (Fig. I). Height of clypeus nearly equal to half the long axis of ALE. Chelicerae: slightly porrect; nearly parallel; without special modifications. Maxillae and lip apparently typical of the genus. Sternum: moderately raised; longer than wide in ratio of about I $8:$ I 3 ; with three pairs of lateral grooves but with the corresponding lobes poorly indicated; procurved sternal suture barely indicated; posterior end squarely truncated between bases of fourth coxae which are separated by nearly I.5 times their width; third coxae globose, others somewhat elongated. Legs: 4123 in order of length; tibial index of first leg 9, of fourth leg 8; no true spines seen on legs or palps; palpal tarsus with a tuft of broadened hairs, so often seen in species in this family, on prolateral side of cymbium; trichobothria observed on tibiae and 

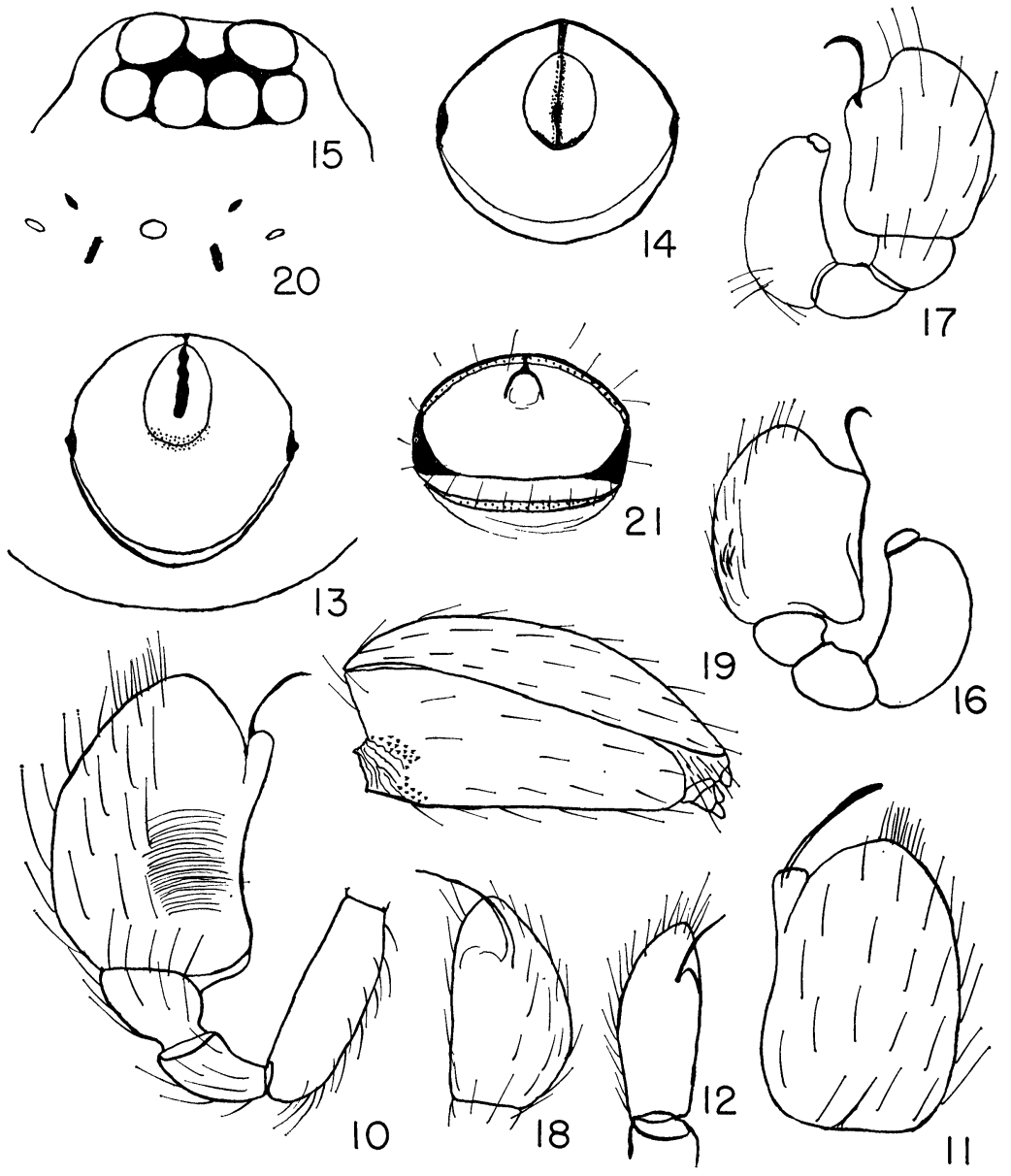

Figures 10-14. Scaphiella gertschi Chickering. Figs. 10-11. Left palp of male; prolateral and nearly dorsal views, respectively. Fig. 12. Right palpal tarsus; nearly ventral view. Figs. 13-14. Epigynal areas; two variations in appearance of this region. Figures 15-21. Scaphiella kalunda sp. nov. Fig. 15. Eyes of male from above. Figs. 16-17. Left male palp; prolateral and retrolateral views, respectively. Fig. 18. Left male palpal tarsus; nearly ventral view. Fig. 19. Male abdomen; lateral view; left side. Fig. 20. Genital area of male from below. Fig. 21. Epigynal area from below. 
metatarsi. Abdomen: $1.05 \mathrm{~mm}$ long; $.46 \mathrm{~mm}$ wide about one fifth of its length from posterior end where it is widest; considerably compressed laterally; ventral scutum reaches posteriorly for about two thirds of length of venter and extends dorsally to cover lateral surfaces but leaves nearly the whole dorsum uncovered; a very narrow sclerite surrounds the spinnerets ventrally and laterally but not dorsally; spinnerets appear typical of the genus; openings of booklungs and tracheal spiracles quite distinct. Epigynal area quite distinctive (Fig. 2). Color in alcohol: all parts, except those abdominal areas not covered by scutum, are orange yellow with minor variations; the unshielded areas are nearly white.

\section{Scaphiella barroana Gertsch}

Scaphiella barroana Gertsch, 1941: 10, figs. 20-22. Male holotype and paratypes of both sexes from Barro Colorado Island, Panama Canal Zone are in the American Museum of Natural History, N. Y. City. Chickering, 1951: 234.

One male taken January 28, 1958; one male taken May I5, I964; twelve specimens all taken between I94I and 1946 in a Berlese funnel by Dr. James Zetek constitute my entire collection of this species. Dr. Gertsch has loaned me two males; one taken in July, 1938 and the other taken Nov. I952-March, 1953 in a Berlese funnel by Dt. Zetek. All of these have been taken on Barro Colorado Island, Panama Canal Zone. The palpal features of the male seem to be fairly clear and quite stable. The epigynal area is less clearly defined and appears to be somewhat variable.

\section{Scaphiella curlena sp. nov.}

Figures 3-4

Holotype. The female holotype is from Jamaica, W. I., St. Catherine Parish, Guanaboa Vale, December 4, 1957. The name of the species is an arbitrary combination of letters.

Description. Total length, including bases of chelicerae, I.5 I $\mathrm{mm}$. Carapace $0.57 \mathrm{~mm}$ long; $0.44 \mathrm{~mm}$ wide opposite second coxae where it is widest; $0.2 \mathrm{~mm}$ tall; nearly level along middorsal region from PME to beginning of posterior declivity opposite anterior border of third coxae; posterior declivity with a concavity a little below the middle and with two long, stiff bristles at top; not notably granulate. Eyes: six as usual in a compact group; viewed from above, posterior row gently procurved. Ratio of eyes ALE : PME : PLE $=6.5: 5.5: 4.5$. ALE separated from one another by a little less than half their radius (Fig. 3); ALE barely separated from PLE; PME contiguous to one another and to PLE. Height of 
clypeus about equal to diameter of ALE. Chelicerae, maxillae and lip apparently typical of females of the genus in the region under study. Sternum: with only moderately developed marginal grooves and lobes; anterior coxae somewhat elongated; all other coxae nearly globose; not extended between fourth coxae which are separated by about $\mathrm{I} .5$ times their width. Legs: 4123 in order of length; tibial index of first leg 12 , of fourth leg 10. No true spines observed on legs or palp but many stiff bristles are present. The palpal tarsus is enlarged and provided with the cluster of widened hairs about as shown in Figure 53 for $S$. williamsi Gertsch. Abdomen: considerably compressed laterally; general features of ventral scutum and sclerite associated with spinnerets appear to be typical of females of the genus; the epigynal area (Fig. 4) appears to be obscurely distinctive with some variations among the few specimens assigned to the species. Color in alcohol: the dorsal abdominal region, lacking the scutum, is nearly white with a faint darker reticulation; all other parts brownish yellow with some variation.

Records. Four paratype females from Jamaica, W. I. are assigned to this species as follows: St. Catherine Parish, Portland Ridge, Dec. 2, I949 (R. P. Bengry and C. B. Lewis); St. Catherine Parish, Port Henderson, May 4, 1956 (C. C. Hoff); St. Thomas Parish, Morant Point, May 6, I956 (C. C. Hoff).
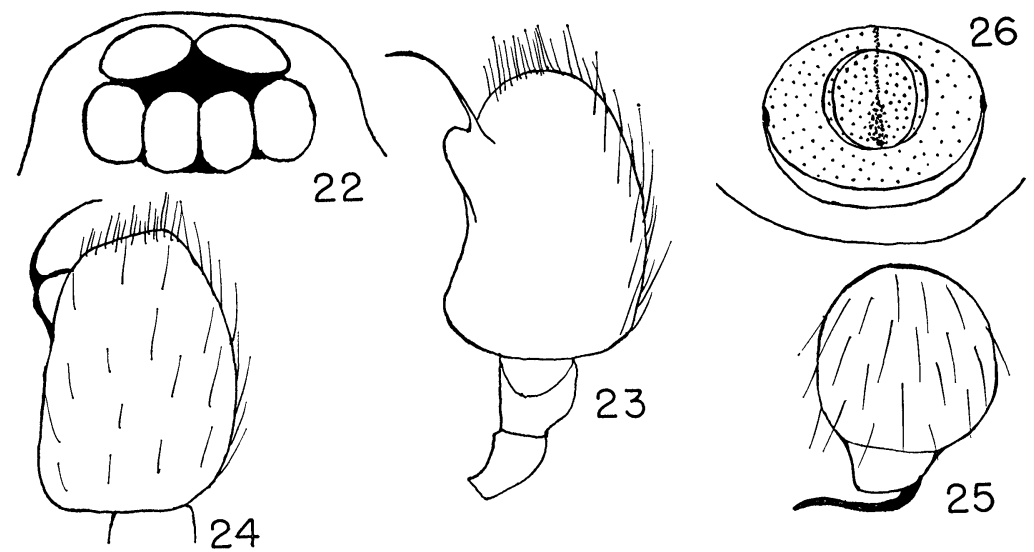

Figures 22-26. Scaphiella schmidti Reimoser. Fig. 22. Eyes of male from above. Fig. 23. Male palpal tarsus, tibia and patella; nearly retrolateral view. Fig. 24. Male palpal tarsus; dorsal view. Fig. 25. Male palpal tarsus; viewed from distal end. Fig. 26. Epigynal area from below. 


\section{Scaphiella cymbalaria Simon}

Figures 5-9

Scaphiella cymbalaria Simon, 1891: 561, no figs. Male and female syntypes from St. Vincent, B. W. I. are in the British Museum (Natural History). Simon, 1893: 288, 300, figs. 257-258; Petrunkevitch, 1911: 129; 1928: 88;

Roewer, 1942: 289; Bonnet, 1958: 3940.
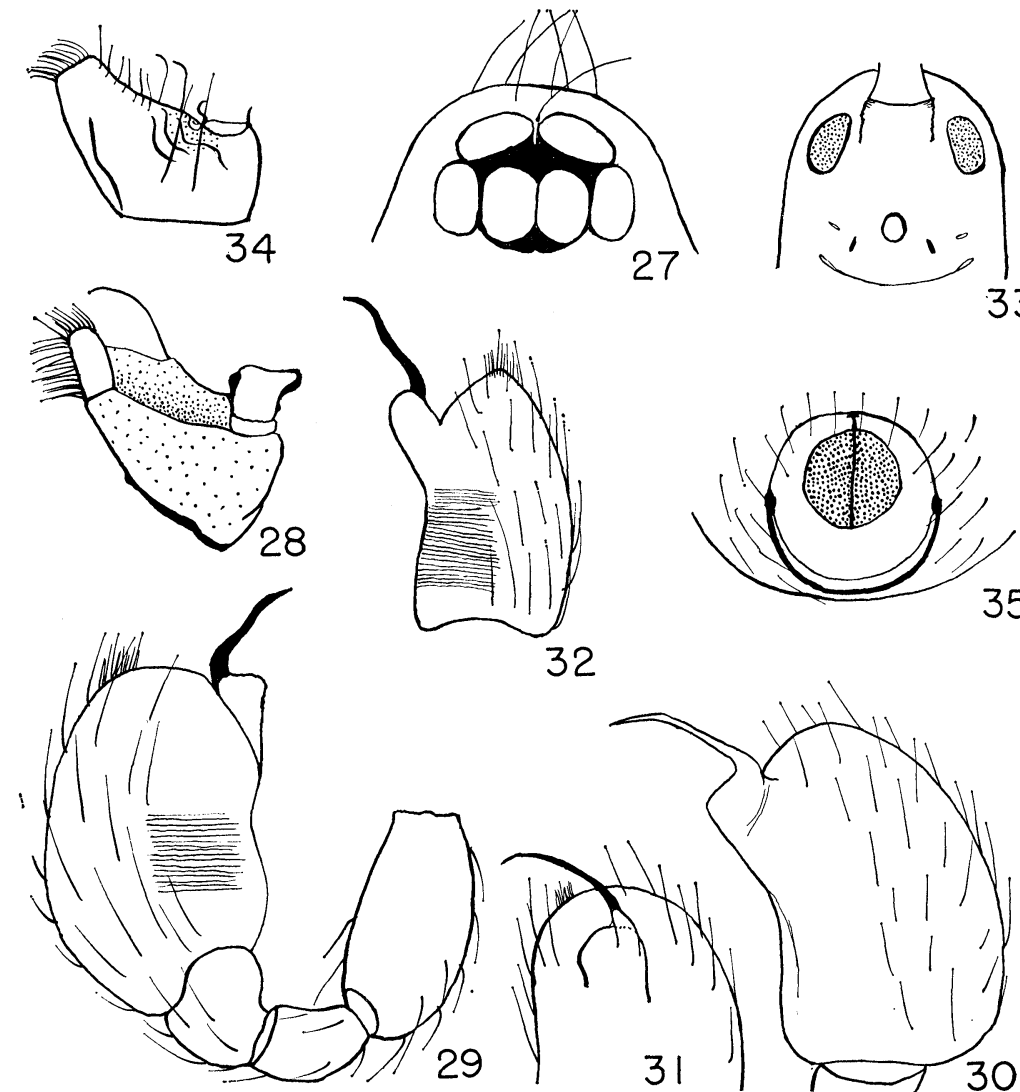

35

Figures 27-35. Scaphiella scutata sp. nov. Fig. 27. Eyes of male from above. Fig. 28. Left maxilla of male from below. Fig. 29. Left male palp; prolateral view. Fig. 30 . Left male palpal tarsus; retrolateral view. Fig. 31. Distal end of left palpal tarsus; ventral view. Fig. 32. Right male palpal tarsus; prolateral view. Fig. 33. Anterior portion of venter of male from below. Fig. 34. Left maxilla of female paratype from below. Fig. 35 . Epigynal area from below. 
From a male and a female on loan from the British Museum (Natural History) the following facts have been derived.

Male. Total length $\mathrm{I} .56 \mathrm{~mm}$. Carapace $0.64 \mathrm{~mm}$ long; $0.53 \mathrm{~mm}$ wide opposite second coxae where it is widest; $0.23 \mathrm{~mm}$ tall; somewhat raised just behind PME and then level along middorsal region to beginning of posterior declivity. Eyes: six in a compact group as usual (Fig. 5); ALE well separated; with little pigment in ocular area; viewed from above, posterior row slightly procurved; boundaries of clypeus obscure but height is probably nearly equal to diameter of ALE. Chelicerae: each with a curious cone-shaped projection in front near base (Fig. 5). Maxillae and lip appear essentially as described for other species. Sternum: scutiform; convex; moderately lobed opposite coxae along margin but not deeply grooved as in Dysderina (Fig. 6); fourth coxae separated by a little more than their width; terminated opposite bases of fourth coxae; third coxae globose and all others somewhat more elongated. Legs: 4I23 in order of length with first and fourth only slightly different. Palp: both tarsi fully developed; essential features shown in Figure 7 ; other segments without special modifications. Abdomen: dorsal scutum covers entire dorsum and extends laterally nearly to ventral scutum so that very little of the unshielded surface shows; no sclerite has been observed in association with the spinnerets. Color in alcohol: as it now appears after long preservation the color is a light yellowish.

Female. Total length $1.73 \mathrm{~mm}$. Carapace $0.64 \mathrm{~mm}$ long; 0.49 $\mathrm{mm}$ wide opposite second coxae where it is widest; about $0.21 \mathrm{~mm}$ tall. Eyes: essentially as in male but posterior row slightly more procurved than in that sex and the ALE are somewhat closer together; apparently a slight asymmetry in the PME. Sternum essentially as in male with grooves about the same. Abdomen: with a well defined ventral scutum (Fig. 8) somewhat restricted in lateral dorsal extensions so that a large part of both dorsum and dorsolateral parts are left bare and white in coloration; the sclerite associated with the spinnerets is present but hardly visible; epigynal area as shown in Figure 9. Other features essentially as in male.

\section{Scaphiella gertschi Chickering \\ Figures IO-I4}

Scaphiella gertschi Chickering, 1951: 235, figs. 24-27. The male holotype from Barro Colorado Island, Panama Canal Zone is in the Museum of Comparative Zoology.

In I95 I the only male available for study was the holotype. Since that time I have collected a large number of both sexes. For example, over IOO were taken on one day at Summit, Canal Zone and nu- 
merous specimens are also in the collection from Jamaica, W. I. A. few additions should be made to my original description of the species as follows: When the holotype was described it was noted that the right palp was poorly developed. At that time the condition was regarded as an anomaly and should have been mentioned but this was inadvertently omitted. Figures IO-I2, drawn from a male collected in Jamaica, will show the essential features of both left and right palpal tarsi. Very fine striations on the prolateral surface of the left palpal tarsus were first seen in a male from the Panama Canal Zone but these have now been observed in numerous males from Panama and Jamaica, W. I. (Fig. Io). These striations have also been found on the left palpal tarsi of Scaphiella scutata sp. nov. from Jamaica, W. I. Variations in the appearance of the epigynal area have been noted during the examination of numerous females; Figures I3-I4 are provided to illustrate two of these variations.

Records. One male was collected at El Volcan, Panama in August, 1950. All others in the collection, now numbering several hundred, have been collected in numerous localities in the Canal Zone from I950 to 1964 . I also now have numerous specimens of both sexes from Jamaica, W. I. These have been taken in the following named parishes during my three visits to this island since 1950: Clarendon, Kingston and, especially, St. Andrew.

\section{Scaphiella kalunda sp. nov.}

\section{Figures I5-2 I}

Holotype. The male holotype is from St. John, U. S. Virgin Islands, July 23, 1966. The name of the species is an arbitrary combination of letters.

Description. Total length about $1.48 \mathrm{~mm}$ (cephalothorax and abdomen detached but in good condition). Carapace $0.6 \mathrm{~mm}$ long; $0.44 \mathrm{~mm}$ wide opposite interval between first and second coxae where it is widest; surface smooth and shiny; without a median thoracic groove or pit; posterior border recurved; gently arched from PME along middorsal region to beginning of posterior declivity. Eyes: six in two rows and in a compact group as usual; posterior row slightly procurved viewed from above; ratio of eyes ALE : PME : PLE $=5: 4: 3.5$; some irregularity and asymmetry noted; ALE separated by about two fifths of their diameter (Fig. I5); ALE separated from PLE only by a line and from PME by about one fifth of their diameter; PME contiguous at one point and barely separated from PLE. Height of clypeus equal to nearly 1.5 times the diameter of ALE. Chelicerae, maxillae and lip apparently quite 
typical of males of the genus but fragility of the holotype and scarcity of parataypes prevents close examination. Sternum: quite convex; longer than wide in ratio of about $7: 6$; bluntly terminated between bases of fourth coxae which are separated by nearly 1.5 times their width; continued laterally between coxae; surface smooth with faint lobulations along margin; sternal suture conspicuous and slightly recurved; with a moderate supply of black bristles near margin and with a group of five or six of these at posterior end; first coxae somewhat elongate but all others quite globose. Legs: 4I23 in order of length; tibial index of first leg 12 , of fourth leg II; true spines are lacking but spiniform bristles are present. Palp: essential features shown in Figures I6-18; both right and left palps fully developed; palpal tarsus short and broad; palpal femur somewhat inflated. Abdomen: slender; dorsal and ventral scuta cover nearly entire surface (Fig. 19); the usual sclerite partially surrounds the spinnerets; obscure genital area as shown in Figure 20; minute cusps present at base of pedicel. Color in alcohol: essentially as described for $S$. barroana and $S$. williamsi by Dr. Gertsch (194I) with minor variations.

Female paratype. Total length $1.55 \mathrm{~mm}$. Carapace $0.55 \mathrm{~mm}$ long; about $0.42 \mathrm{~mm}$ wide opposite second coxae where it is widest; $0.18 \mathrm{~mm}$ tall; only slightly arched along middorsal region from PME to beginning of posterior declivity. Eyes essentially as in male. Chelicerae, maxillae and lip all essentially typical of females of the genus so far as observed. Sternum: convex; marginal lobulation hardly discernible; otherwise essentially as in male. Legs essentially as in male. Palp: tarsus somewhat inflated; a group of flattened hairs on prolateral side near base as in male. Abdomen: dorsal scutum lacking in typical fashion; ventral scutum somewhat less extensive than in male; epigynal area somewhat distinctive (Fig. 21). Color in alcohol: parts not covered by abdominal scutum are white; elsewhere color is similar to that of male but somewhat lighter with slight variations.

Records. The described female paratype was taken on July 25, 1966 in the same general locality as the holotype male. A male taken in the same general locality on July 24,1966 is, with some uncertainty, regarded as a paratype.

\section{Scaphiella schmidti Reimoser}

Figures 22-26

Scaphiella schmidti Reimoser, 1939: 380, figs. 13A-13B. Male and female syntypes from the San José, Costa Rica are in the Naturhistorisches Museum in Wien. Roewer, 1942: 289. 
Reimoser furnished two simple figures to accompany his description of the species. As a result of an examination of the male and female on loan from the Naturhistorisches Museum in Vienna I have prepared Figures 22-26 to further clarify the status of this species. Eyes of male typical of the genus (Fig. 22). Eyes of female similar to those of male but the posterior row is very slightly recurved, measured by posterior borders and viewed from above. The essential features of the male palp are shown in Figures 23-25. The epigynal area of the female appears to be obscurely distinctive (Fig. 26). It is quite different from the epigynal areas of the three species known from Panama. A female from San Jose, Costa Rica, collected by Enrique Schmidt, was, for a time, considered to be a new species. Careful comparison with the female of Scaphiella schmidti Reimoser has raised doubts regarding its status as a new species and, for this reason, it is tentatively placed in the above named species.

\section{Scaphiella scutata sp. nov.}

\section{Figures 27-35}

Holotype. The male holotype is from Jamaica, W. I., St. Andrew Parish, Liguanea, November I4, 1957. The name of the species is a Latin adjective meaning "armed with a shield."

Description. Total length $1.8 \mathrm{~mm}$ (exclusive of extended spinnerets). Carapace $0.73 \mathrm{~mm}$ long; $0.62 \mathrm{~mm}$ wide opposite interval between second and third coxae where it is widest; $0.27 \mathrm{~mm}$ tall; with four long, stiff, erect hairs between PME and upper part of steep posterior declivity; with several shorter hairs just behind PE and a few similar hairs elsewhere. Eyes: six in a compact group typical of the genus; posterior row very slightly procurved, measured by posterior borders and viewed from above; posterior row occupies about five eighths of width of carapace at that level. Ratio of eyes ALE : PME : PLE = about 7.5: $7: 7$ (some asymmetry noted; long axis always used for measurements). ALE just separated from one another and with a long, slender bristle between them; only separated from PLE by a line; separated from PME by about three eighths of their long axis (Fig. 27). PME contiguous to one another and to PLE. Posterior row wider than anterior row in ratio of about $4: 3$. Height of clypeus equal to slightly more than diameter of ALE; clypeus with a row of four long, stiff bristles and with a pair of similar bristles in the middle below ALE. Chelicerae: vertical; essentially parallel; fairly robust; basal segment about $.22 \mathrm{~mm}$ long; fang normal, moderately robust; no definite teeth observed along fang groove. Maxillae: strongly convergent, coming to lie 
almost transversely; with a deep trough on external surface; medial ends terminate in what appears to be a characteristic manner (Fig. 28). Lip: essentially typical of males of the genus; sternal suture not observed and, therefore, lip is regarded as immobile. Sternum: convex; third coxae subglobose, others more elongated; otherwise essentially typical of the genus. Legs: $4 \mathrm{I} 23$ in order of length; tibial index of first leg II, of fourth leg 8; spines appear to be absent as usual but there are many erect bristles, especially along dorsal surface of femora; two tarsal claws as usual; trichobothria observed on tibiae and metatarsi. Palp: essential features shown in Figures 29-32; left palp fully developed and, in general, quite typical of the genus; right palp not inflated and much smaller; the conspicuous unilaterality of the functional palp is the normal condition in this species as in $S$. gertschi Chickering and not an anomaly as at first thought; some variation in the degree of development of the right palpal tarsus has been noted, however, among the many individuals available for study; fine striations are clearly visible on the prolateral
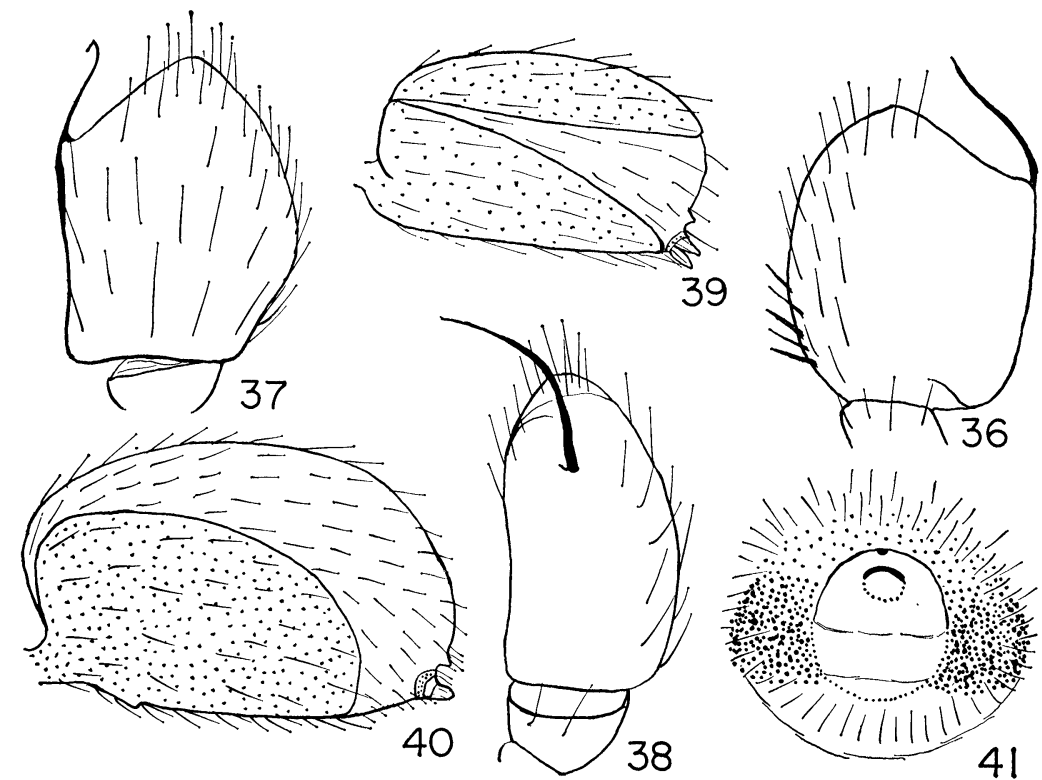

38

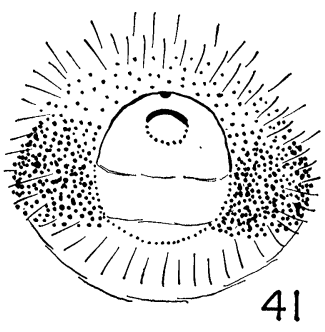

Figures 36-41. Scaphiella septella sp. nov. Figs. 36-38. Male palpal tarsus; prolateral, retrolateral and ventral views, respectively. Figs. 39-40. Abdomen of male and female, respectively; left lateral side. Fig. 41. Epigynal area from below. 
surface of both palpal tarsi. Abdomen: relatively long and narrow; I.I $4 \mathrm{~mm}$ long; $0.53 \mathrm{~mm}$ wide; $0.66 \mathrm{~mm}$ tall; compressed laterally; area of genital aperture, tracheal spiracles, and openings of booklungs as shown in Figure 33; dorsal and ventral scuta as usual in males of the genus. Color in alcohol: in general as described by Gertsch (194I) and Chickering (I95I) but the abdominal color is considerably altered by the presence of numerous, irregular, subchitinous, dark spots which are quite variable.

Female paratype. Total length $2.1 \mathrm{I} \mathrm{mm}$. Carapace about 0.79 $\mathrm{mm}$ long; $0.64 \mathrm{~mm}$ wide opposite second coxae where it is widest; $0.28 \mathrm{~mm}$ tall; otherwise essentially as in holotype. Eyes: in general as in holotype; ratio of eyes ALE : PME : PLE $=8: 7: 7.5$. Maxillae: strongly convergent; relatively robust; less highly modified than in male (Fig. 34). Chelicerae and lip apparently typical of females of the genus. Sternum: nearly as wide between second coxae as long; convex; not extended between fourth coxae which are separated by nearly $\mathrm{I} .5$ times their width. Legs: 4I23 in order of length as usual; tibial index of first and fourth legs ro. Palp without a terminal claw. Trichobothria observed on tibiae, metatarsi and on palpal tibiae but exact number and placement not determined. Abdomen: essentially as in male except for the absence of the dorsal scutum and the characters of the epigynal area (Fig. 35). Color in alcohol: also essentially as in holotype except for the exposed dorsal region of the abdomen which is whitish with darker reticulations.

Records. The described female paratype was taken with the male holotype. The species appears to be common in Jamaica, W. I. I have it in my collection from numerous localities in St. Andrew Parish where it seems to be abundant. More than one hundred specimens of both sexes were taken with the holotype on Nov. I4, 1957. I also have it from St. Ann, Runaway Bay, June 23, 1954; from three different localities in St. Catherine Parish; Kingston Parish, Palisadoes Area, Nov. I, 1957 and July 2I, 1958 (M. W. Sanderson); St. Thomas, Morant Bay, October 29, 1957. Two males and a female were collected on Curaçao, Nederl. Antilles, Willemstad, Dec. 24, 1962 and at Piscadera Baai, Dec. 18-30, 1962 (Dr. H. W. and Lorna Levi).

Scaphiella septella sp. nov.

Figures 36-4I

Holotype. The male holotype is from Virgin Gorda, British 


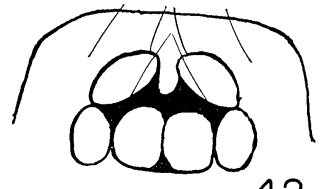

42
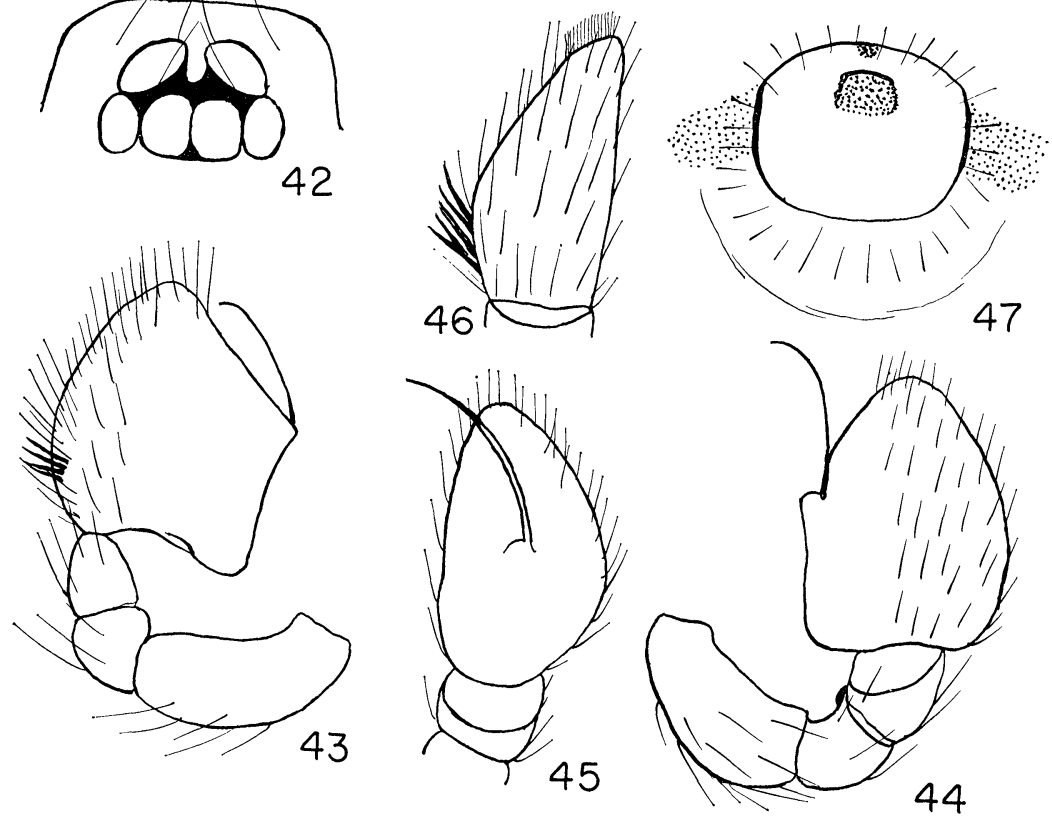

Figures 42-47. Scaphiella simla sp. nov. Fig. 42. Eyes of male from above. Figs. 43-44. Left palp of male; prolateral and retrolateral views, respectively. Fig. 45. Left palpal tibia and tarsus of male; ventral view. Fig. 46. Right palpal tarsus of female; dorsal view. Fig. 47. Epigynal area from below.

Virgin Islands, August I7-22, I966. The name of the species is an arbitrary combination of letters.

Description. Total length $1.27 \mathrm{~mm}$. Carapace $0.54 \mathrm{~mm}$ long; 0.4I mm wide opposite second coxae where it is widest; about 0.22 $\mathrm{mm}$ tall; nearly level along middorsal region to beginning of posterior declivity the first half of which is precipitous; otherwise typical of males of the genus. Eyes: six as usual in two rows in a compact group; posterior row moderately procurved, seen from above. Ratio of eyes ALE : PME : PLE = 5.5: $5: 4$. ALE circular, others oval. ALE barely separated from one another and contiguous to PLE; separated from PME by about three-tenths of their diameter. PME contiguous to one another and to PLE. Clypeus quite porrect; height slightly greater than diameter of ALE. Chelicerae: essentially vertical; concave medially in distal half so that the organs are greatly narrowed in that region; from near the beginning of the concavity 
of each chelicera there arises a long, slender spine and two curious, black structures similar to those recorded in 195 I for $S$. barroana Gertsch. Maxillae apparently typical of males of the genus. Lip: triangular and essentially typical of males of the genus. Sternum: convex as usual, without grooves or lobes; longer than wide in ratio of about $8: 7$; terminated opposite bases of fourth coxae which are separated by about $\mathrm{I} .33$ times their width. Legs essentially typical of the genus. Palp: essential features shown in Figures 36-38; both palps fully developed; no prolateral striations observed on palpal tarsi. Abdomen: slender; $0.72 \mathrm{~mm}$ long exclusive of the slightly exposed pedicel; about $0.36 \mathrm{~mm}$ wide two thirds of its length from base; with a considerable area not covered by scuta (Fig. 39); the sclerite partly surrounding the spinnerets as usual in the genus. Color in alcohol: parts of abdomen not covered by scuta white; all other parts of body and appendages light yellowish with variations.

Female paratype. Total length $\mathrm{I} .63 \mathrm{~mm}$. Carapace $0.55 \mathrm{~mm}$ long; $0.42 \mathrm{~mm}$ wide opposite second coxae where it is widest; $0.2 \mathrm{I}$ $\mathrm{mm}$ tall; gently arched from PME along middorsal region to beginning of steep posterior declivity; otherwise essentially typical of females of the genus. Eyes essentially as in male. Chelicerae, convergent maxillae and triangular lip all essentially typical of females of the genus. Sternum: convex as usual; longer than wide in ratio of $6: 5$; faintly lobulated along margin; squarely truncated between bases of fourth coxae which are separated by I.6 of their width. Legs essentially as in male. Abdomen: in general essentially typical of females of the genus; with single scutum as shown in Figure 40; considerably compressed laterally; epigynal area obscurely distinctive (Fig. 4I). Color in alcohol: unshielded area of abdomen white; scutum somewhat darker than in male; otherwise essentially as in the holotype.

Record. The described female paratype together with one other female taken during the same period as that in which the holotype was collected.

\section{Scaphiella simla sp. nov.}

Figures $42-47$

Holotype. The male holotype is from Trinidad, W. I., Arima Valley, Simla, April 19, 1964. The name of the species is a noun used in apposition after the locality where the holotype was collected.

Description. Total length $1.76 \mathrm{~mm}$. Carapace $0.7 \mathrm{~mm}$ long; 0.55 wide opposite second coxae where it is widest; about $0.26 \mathrm{~mm}$ tall; very gently arched from PME to beginning of moderately steep posterior declivity which is quite granulate; ventral margin also granulate; otherwise essentially typical of the genus. Eyes: six as 
usual in a compact group; outlines clear and distinct; posterior row occupies about three-fifths of width of carapace at that level and is slightly procurved, viewed from above. Ratio of eyes ALE : PME : PLE $=7: 6: 5.5$. ALE separated from one another by nearly two-sevenths of their diameter (Fig. 42); from PLE by a line and from PME by about one-third of their diameter. PME contiguous to one another and to PLE. Clypeus somewhat porrect and with height equal to slightly more than the diameter of ALE. Chelicerae, maxillae and lip all apparently typical of males of the genus with minor variations. Stenum: strongly convex; longer than wide in ratio of 2 I : 19; plainly lobed along margins with bounding grooves well developed; posterior end not extended between fourth coxae which are separated by about I.5 times their width; third coxae globose, all others somewhat elongated with first somewhat the longest. Legs : 4I23 in order of length; tibial indices of first and fourth legs 9; no true spines on legs. Palp: general features typical of males of the genus as seen in this study; distinctive features shown in Figures 43-45; both palps fully developed. Abdomen: typical of males of the genus in general; scuta cover somewhat less of the abdominal surface than in $S$. kalunda sp. nov.; sclerite associated with the spinnerets as usual; genital area also as usual in males of the genus. Color in alcohol: carapace, sternum, legs, mouth parts except palpal tarsus and abdominal scuta all a rich, bright orange with some variations; palpal tarsus yellowish; abdominal areas not covered by scuta are white.

Female paratype. Total length $1.95 \mathrm{~mm}$. Carapace $0.77 \mathrm{~mm}$ long; $0.58 \mathrm{~mm}$ wide; about $0.26 \mathrm{~mm}$ tall; slightly raised just behind $\mathrm{PME}$ and then almost level along middorsal region to beginning of posterior declivity; otherwise as in male. Eyes essentially as in male with minor variations. Height of porrect clypeus about I.3 times the diameter of ALE. Chelicerae, maxillae and lip all typical of females of the genus without apparent modifications. Sternum: essentially as in male with marginal lobes and grooves as in that sex; fourth coxae separated by nearly twice their width. Palp as usual in females of the genus; tarsus essentially as in Figure 46. Legs essentially as in male. Abdomen: in general typical of females of the genus; dorsal scutum lacking; ventral scutum covering ventrolateral sides; sclerite partially surrounding spinnerets as in male; epigynal area obscurely distinctive (Fig. 47). Color in alcohol: as in male except for the clear white dorsal, abdominal region where scutum is lacking; with a sparse covering of black hair. 


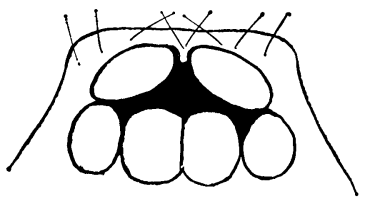

48

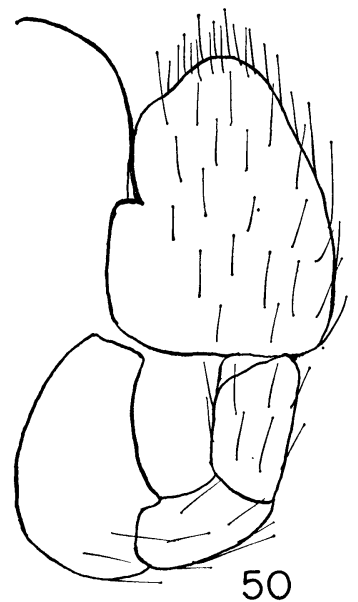

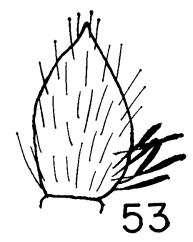
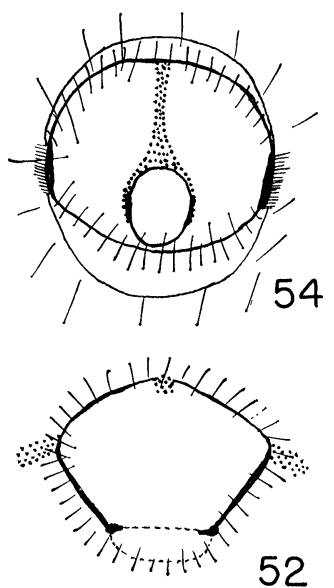

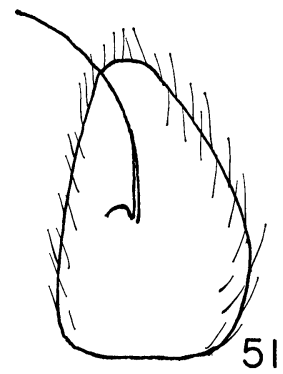

Figures 48-52. Scaphiella weberi sp. nov. Fig 48. Eyes of male from above. Fig. 49. Left male palpal tarsus; prolateral view. Fig. 50. Left male palp; retrolateral view. Fig. 51. Left male palpal tarsus; ventral view. Fig. 52. Epigynal area from below. Figures 53-54. Scaphiella williamsi Gertsch. Fig. 53. Left palpal tarsus of female; dorsal view. Fig. 54. Epigynal area from below.

Record. The described female paratype is from the same locality as the holotype, April 16, 1964. Three paratype males and two additional female paratypes were taken in April, 1964. One male and a female are also in the collection from Trinidad, W. I.; collected by $\mathrm{N}$. A. Weber with no date indicated.

\section{Scaphiella weberi sp. nov.}

Figures 48-52

Holotype. The male holotype is from Trinidad, W. I., with no date of collection given. The species is named after the collector, Dr. N. A. Weber. 
For some time the holotype of this species was, with some uncertainty, placed with $S$. simla sp. nov. After re-examination and comparison the decision has been made to regard it as the representative of a new species as presented here. This decision has been made on the basis of several minute differences, the most important of which are the following: it is considerably smaller than $S$. simla sp. nov.; the ALE are barely separated; the palpal femur is relatively shorter and more inflated; the palpal patella and tibia are relatively longer. The female paratype is plainly quite different from the female of $S$. simla sp. nov.

Description. Total length, including somewhat extended spinnerets and bases of chelicerae, I.23 mm. Carapace $0.48 \mathrm{~mm}$ long; $0.42 \mathrm{~mm}$ wide opposite second coxae where it is widest; about 0.13 $\mathrm{mm}$ tall; somewhat arched from PME to beginning of steep posterior declivity; without a median thoracic groove or pit. Eyes: six in two rows and in a compact group as usual; posterior row slightly procurved, measured by posterior borders and seen from above. Ratio of eyes ALE : PME : PLE = about 6.5 : $5.5: 5$ (some distortion, PLE not clearly outlined). ALE barely separated; contiguous to PLE and separated from PME by less than half their width (Fig. 48). PME contiguous to one another and to PLE. Height of clypeus nearly equal to diameter of ALE. Chelicerae, maxillae and lip apparently typical of males of the genus. Sternum: convex as usual; moderately lobed along lateral margins; longer than wide in ratio of about Io : 9; posterior end bluntly rounded and extended between fourth coxae which are separated by five-thirds of their width; third coxae globose, all others somewhat elongated. Legs: probably 4I23 in order of length (fourth legs missing); tibial index of first leg Io; no true spines observed. Palp: general features typical of males of the genus; Figures 49-5 I show essential features; lateral tuft of modified hairs present but obscure. Abdomen: with typical scuta covering all but extreme posterior end and a narrow strip between dorsal and ventral scuta; genital aperture a minute, circular opening; otherwise typical of males of the genus. Color in alcohol: carapace, sternum and abdominal scuta a light yellowish brown; legs and mouth parts yellowish except palpal tarsus which is nearly white.

Female paratype. Total length $1.8 \mathrm{~mm}$, including considerably extended chelicerae and spinnerets; exclusive of these parts, total length is $1.63 \mathrm{~mm}$. Carapace $0.64 \mathrm{~mm}$ long; $0.48 \mathrm{~mm}$ wide opposite posterior border of second coxae where it is widest; about $0.19 \mathrm{~mm}$ tall; only slightly arched along middorsal region to beginning of steep 
posterior declivity; otherwise essentially typical of females of the genus. Eyes: ALE somewhat further separated than in male but outlines are obscure and with some irregularities; otherwise essentially as in male. Chelicerae, maxillae and lip apparently typical of females of the genus. Sternum: general features as usual; marginal lobes moderately well developed; posterior end squarely truncated and just opposite bases of fourth coxae which are separated by nearly twice their width. Legs as usual in the genus. Palp: with the tarsus somewhat enlarged as usual. Abdomen: with ventral scutum as usual in females of the genus; sclerite surrounds the spinnerets for about two-thirds of the complete distance; spinnerets as usual; epigynal area (Fig. 52) is somewhat distinctive. Color in alcohol: typical of the genus in general; areas of abdomen not covered by scutum are a clear white; other parts somewhat darker than in male.

Records. The described female paratype, one other female paratype and the cephalothorax of a male are all assigned to this species. Two other females are tentatively assigned to this species but with considerable uncertainty. These were all collected by Dr. N. A. Weber but with no date of collection indicated.

\section{Scaphiella williamsi Gertsch}

Figures 53-54

Scaphiella williamsi Gertsch, 1941: 11, figs. 18-19. The male holotype from Barro Colorado Island, Panama Canal Zone is in the American Museum of National History, New York City. Chickering, 1951: 239.

Dr. Gertsch had only the holotype in I94I. In I95 I I had a female which seemed to be the female of this species and at the present time there is no reason to believe that an error was made at that time. Since I95 I I have acquired three males and six females from Barro Colorado Island, Summit Gardens and Gatun all in the Panama Canal Zone. Two males from Barro Colorado Island have been on loan from the American Museum of Natural History. The female palpal tarsus is shown in Figure 53. The epigynal area in females seems to follow a fairly consistent pattern with some minor variations. Figure 54 shows what appears to be a fairly typical epigynal area.

Bonnet, Pierre

\section{BIBLIOGRAPHY}

1958. Bibliographia Araneorum. Vol. 2(4). Toulouse.

Chickering, A. M.

1951. The Oonopidae of Panama. Bull. Mus. Comp. Zool., 106(5): 207-245, 31 figs. 
GerTsch, W. J.

1941. Report on some Arachnids from Barro Colorado Island, Canal Zone. Amer. Mus. Novitates, 1146: 1-14, 4 pls.

Petrunkevitch, Alexander

1911. A synonymic index-catalogue of spiders of North, Central, South America, etc. Bull. Amer. Mus. Natur. Hist., 29: 1-809.

Reimoser, Eduard

1939. Wissenschaftliche Ergebnisse der Österreichischen biologischen Expedition nach Costa Rica. Die Spinnenfauna. Ann. des Naturhist. Mus. in Wien, 50:328-386, 14 figs.

RoEwer, C. Fr.

1942. Katalog der Araneae. 1: 1-1040. Bremen.

Simon, EUGENe

1891. On the spiders of the Island of St. Vincent. Pt. 1. Proc. Zool. Soc. London, Nov. 17, 1891: 549-575.

1892-

1895. Histoire naturelle des Araignées. Deuxième edition, Vol. 1. Librairie Encyclopedique de Roret, Paris.

Suman, T. W.

1965. Spiders of the Family Oonopidae in Hawaii. Pacific Insects $7(2)$ : 225-242, 42 figs. 

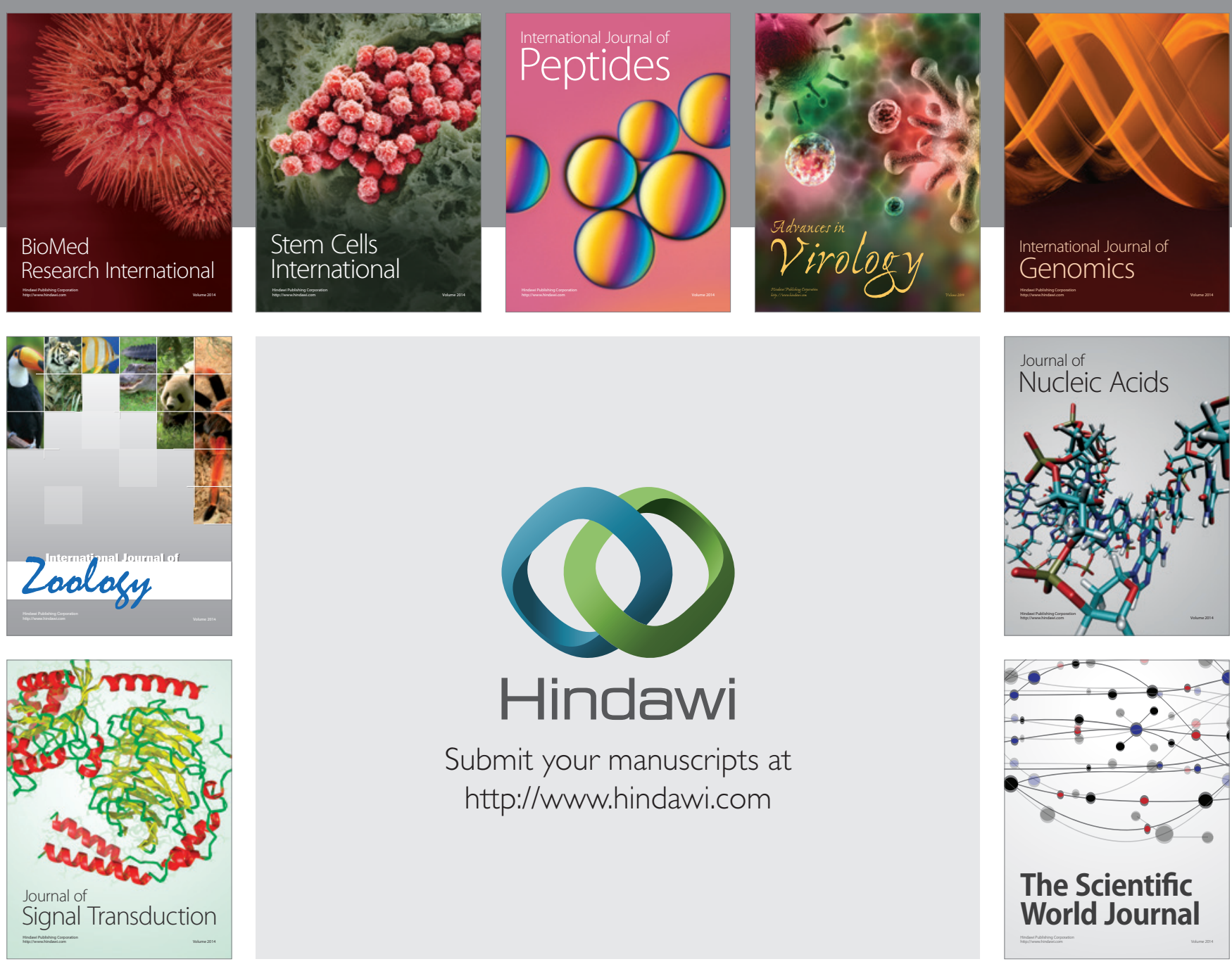

Submit your manuscripts at

http://www.hindawi.com
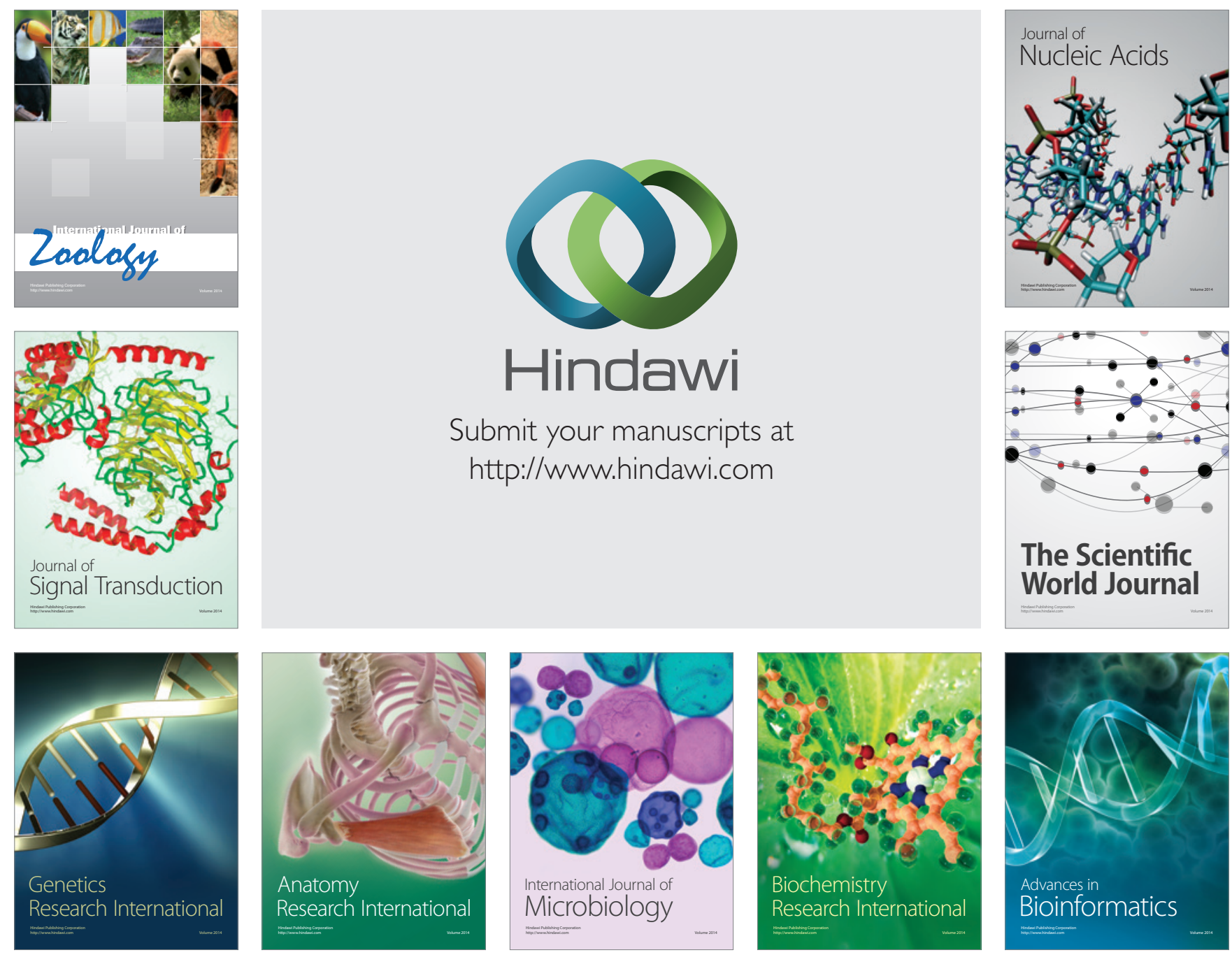

The Scientific World Journal
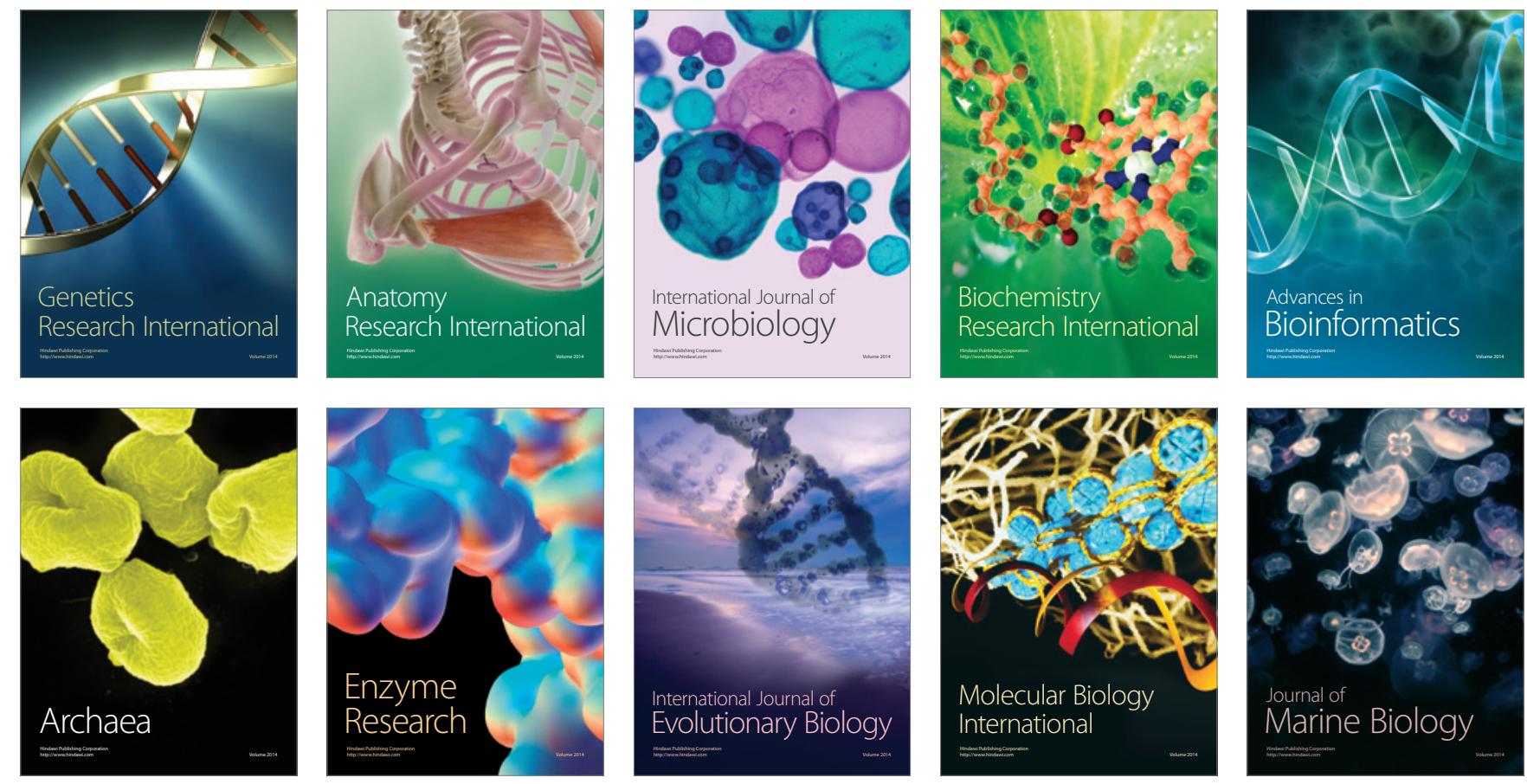